\title{
Determinan Kepatuhan Pajak pada Industri Jasa Konstruksi
}

\author{
J. Purwono ${ }^{1}$
}

${ }^{1}$ Universitas Mpu Tantular, Jl. Puri Kembangan 2 Kedoya, Jakarta Barat

\section{INFO ARTIKEL A B STRACT}

\section{JEL Classification:}

$\mathrm{H} 20$

K34

\section{Keywords :}

lack of money,

tax fairness perception,

tax complexity,

ignorance of tax due, dan probability of detected.
This study aims to determine the factors that affect tax compliance taxpayers and differences in tax revenue Income from the business sector construction services in Indonesia before and after the enactment of Government Regulation No. 51 Year 2008 on Income Tax on Income From Construction Services (PP51 / 2008) Nomo and Government Regulation 40 Year 2009 on Amendment of Government Regulation No. 51 Year 2008 on Income Tax on Income From Construction Services. Population of this research is the taxpayer company's construction services business in Indonesia. Samples were analyzed 104 questionnaires. Determinants of tax compliance are lack of money, tax fairness perception, tax complexity, ignorance of tax due, and the probability of detected. The data quality test validity and reliability. Hypothesis testing is done to test structural models. The results showed that fairness in taxation, regulatory complexity, ignorance, and the possibility of disclosure of deviations is the deciding factor of tax compliance, while lack of money is not proven as a determinant of tax compliance.

\section{A B S T R A K}

Penelitian ini bertujuan untuk mengetahui faktor-faktor yang mempengaruhi kepatuhan perpajakan Wajib Pajak dan perbedaan penerimaan Pajak Penghasilan dari sektor usaha jasa konstruksi di Indonesia sebelum dan sesudah diundangkannya Peraturan Pemerintah Nomor 51 Tahun 2008 Tentang Pajak Penghasilan Atas Penghasilan Dari Usaha Jasa Konstruksi (PP51/2008) dan Peraturan Pemerintah Nomo 40 Tahun 2009 Tentang Perubahan Peraturan Pemerintah Nomor 51 Tahun 2008 Tentang Pajak Penghasilan Atas Penghasilan Dari Usaha Jasa Konstruksi. Populasi penelitian adalah wajib pajak perusahaan usaha jasa konstruksi Indonesia yang tergabung pada GAPENSI, GAPENRI, AKLI dan AKI, Wilayah DKI Jakarta Raya.. Sampel dianalisis sebanyak 104 kuesioner. Faktor-faktor penentu kepatuhan terdiri lack of money, tax fairness perception, tax complexity, ignorance of tax due, dan probability of detected. Uji kualitas data dilakukan dengan uji validitas dan reliabilitas. Pengujian hipotesis dilakukan dengan uji model structural. Hasil penelitian menunjukkan bahwa keadilan di bidang perpajakan, kompleksitas peraturan, ketidakpedulian, dan kemungkinan terungkapnya penyimpangan merupakan faktor penentu kepatuhan perpajakan, sementara kekurangan uang tidak terbukti sebagai determinan kepatuhan pajak. 


\section{Pendahuluan}

Pajak merupakan sumber utama bagi pembiayaanpengeluarannegaradanpembangunan serta untuk mengatur kegiatan ekonomi dan sarana pemerataan pendapatan masyarakat melalui sebuah kebijakan fiskal yang dilakukan oleh pemerintah. Oleh karenanya kepatuhan terhadap pembayaran pajak merupakan hal krusial yang wajib diperhatikan oleh pemerintah. Pada tanggal 20 Juli 2008 pemerintah Indonesia mengeluarkan Peraturan Pemerintah Nomor 51 Tahun 2008 tentang Pajak Penghasilan atas penghasilan dari usaha jasa konstruksi (PP 51/2008) dan berikutnya 4 Juni 2009 pemerintah melengkapinya dengan Peraturan Pemerintah Nomor 40 Tahun 2009 tentang Perubahan Atas Peraturan Pemerintah Nomor 51 Tahun 2008 tentang Pajak Penghasilan Atas Penghasilan Dari Usaha Jasa Konstruksi (PP 40/2009) yang berlaku sejak 1 Agustus 2008. Kedua Peraturan Pemerintah ini dikeluarkan sebagai pengganti Peraturan Pemerintah Nomor 140 Tahun 2000 (PP 140/2000). Peraturan Pemerintah yang baru ini bertujuan menyederhanakan pengenaan Pajak Penghasilan atas penghasilan dari usaha jasa konstruksi dan memberikan kemudahan serta mengurangi beban administrasi bagi Wajib Pajak agar lebih mudah, lebih adil dan dapat meningkatkan penerimaan negara berupa pajak sehingga iklim usaha di bidang jasa konstruksi tetap kondusif.

Harapan pemerintah dan implementasinya di lapangan akan tergantung kepada kepatuhan perpajakan para Wajib Pajak perusahaan Jasa Konstruksi itu sendiri. Ketidakpatuhan perpajakan yang dilakukan para pengusaha pasti menimbulkan permasalahan perpajakan karena berdasarkan literature penelitian yang dilakukan para peneliti terdahulu menyimpulkan bahwa ketidakpatuhan perpajakan berdampak kepada berkurangnya penerimaan negara dan ini berarti mengurangi kemampuan negara di dalam membiayai pengeluaran-pengeluarannya baik pengeluaran biaya rutin maupun pengeluaran pembangunannya.

Realisasi penerimaan PPh jasa konstruksi tahun 2008 sebesar Rp 5,0 trilyun, pada APBN-P tahun 2009 realisasi penerimaan PPh jasa konstruksi dianggarkan naik menjadi Rp 6,7 trilyun atau naik $33,6 \%$. Kenaikan tersebut diharapkan merupakan hasil dari reformasi administrasi perpajakan dan meningkatnya kepatuhan wajib pajak (Sumber APBN.P 2009). Reformasiyang dimaksud adalah diundangkannya Peraturan Pemerintah Nomor 51 Tahun 2008 Tentang Pajak Penghasilan Atas Penghasilan Dari Usaha Jasa Konstruksi (PP51/2008) dan Peraturan Pemerintah Nomo 40 Tahun 2009 Tentang Perubahan Peraturan Pemerintah Nomor 51 Tahun 2008 Tentang Pajak Penghasilan Atas Penghasilan Dari Usaha Jasa Konstruksi.

Secara umum penelitian tentang perpajakan di Indonesia jika dibandingkan penelitian yang dilakukan di negara-negara maju bisa dikatakan masih sangat sedikit, apalagi penelitian tentang kepatuhan perpajakan. Melalui penelitian empiris tentang kepatuhan perpajakan para wajib pajak di Indonesia yang dilakukan peneneliti diharapkan hasilnya dapat dipakai sebagai referensi oleh pembuat kebijakan dalam upaya mengurangi masalah ketidakpatuhan perpajakan.

Pada akhir-akhir ini masalah kepatuhan perpajakan (tax compliance) mulai banyak diperbincangkan dan disoroti berbagai pihak di Indonesia, terutama oleh karena mencuatnya beberapa kasus penyelewengan perpajakan yang nilainya sangat besar walaupun sebenarnya issue kepatuhan perpajakan ini dari dulu sudah menjadi masalah di seluruh dunia bahkan Andreoni dkk (1996) menemukan cara untuk mengurangi masalah kepatuhan perpajakan merupakan keinginan setiap negara. Menurut Andreoni, Erard dan Feinstein (1996), dipandang dari sudut ilmu ekonomi, kepatuhan perpajakan bisa dilihat dari sudut pandang keuangan publik (public finance), penegakan hukum (law enforcement), desain organisasi (organizational design), penawaran tenaga kerja (labor supply), atau bisa juga sebagai masalah etika (ethic), atau kombinasi dari semua hal tersebut.

Ada dua masalah penelitian yang diteliti. Penelitian yang pertama adalah penelitian tentang 
kepatuhan perpajakan, menggunakan referensi penelitian yang telah dilakukan oleh Ritsema dkk (2003) terhadap para pembayar pajak di Arkansas Amerika Serikat yang menyimpulkan bahwa tax compliance dipengaruhi oleh faktor lack of money, perception of tax fairness, complexity of tax law, ignorance of tax due terhadap tax compliance. Dalam penelitian ini, penelitian Ritsema dkk (2003) dikembangan oleh Peneliti dengan menambahkan satu variabel baru yaitu variabel kemungkinan terdeteksinya ketidakpatuhan perpajakan (probability of being detected) yang menurut laporan Badan Penerimaan Pajak Amerika Serikat (Internal Revenue Services) berdasarkan penelitian Mason \& Calvin (1978), Song \& Yarbourg (1978), Tittle (1980), Richard dan Tittle (1981), Scott dan Grasmick (1981 \& 1982), Furnham (1983), Riggs (1984) kecuali temuan Ritsema dkk ( 2003) yaitu faktor lack of money dan ignorance of tax due, tiga faktor lainnya yaitu perception of tax fairness, complexity of tax law dan probability of being detected dinyatakan mempengaruhi kepatuhan perpajakan (sudah termasuk dalam 14 key variables IRS). Penelitian yang ke dua adalah penelitian tentang perbedaan jumlah pembayaran Pajak Penghasilan Perusahaan yang bergerak di bidang usaha Jasa Konstruksi sebelum dan sesudah diberlakukannya Peraturan Pemerintah Nomor 51 Tahun 2008 Tentang Pajak Penghasilan Final Atas Penghasilan Dari Usaha Jasa Konstruksi (PP51/2008).

\section{Telaah Teori dan Pengembangan Hipotesis}

Berbeda dengan para ekonom, para psikolog tidak berfikir mengenai teori tentang pembayar pajak, dalam kaitan ini sebagai makhluk yang sepenuhnya tidak bermoral, menolak setiap risiko yang mengancam dirinya secara maksimal (risk-averse utility-maximizers). Sebaliknya para psikolog tertarik kepada variabel kunci yaitu variabel bebas dalam pengambilan keputusan menggelapkan pajak, pada faktorfaktor seperti pandangan individu terhadap moral yang bisa diterima dalam penghindaran pajak. Pada penelitian compliance para psikolog ingin mengekplorasi faktor-faktor yang mungkin mempengaruhi perubahan para pembayar pajak dari pengambilan keputusan yang semula pasif ke aktif dan kembali lagi ke pasif. Bagaimana isuisu pajak menjadi memuncak (salient)? Apa yang menyebabkan masyarakat mulai berfikir tentang mengubah perilakunya? Bagaimana bekerjanya pola kebiasaan masyarakat? Para psikolog menginginkan mempertimbangkan kerangka subyektivitas atas pengambilan keputusan pajak.

Andreoni, Erard dan Feinstin (1998) menggunakan teori psikologi dalam kepatuhan pajak, yaitu rasa bersalah (guilty) dan rasa malu (shame), persepsi wajib pajak atas kewajaran dan keadilan atas beban pajak yang mereka tanggung (tax fairness perception), dan pengaruh kepuasan terhadap pelayanan pengelola perpajakan. Menurut Erard dan Feinstein (1994), Harold G. Grasmick dan Robert J. Bursick, Jr, 1990) guilt and shame juga mempengaruhi compliance. Menurut pendapatnya pembayar pajak yang tidak menyampaikan laporan pajak, kelihatannya melakukan antisipasi rasa bersalahnya karena membuat laporan penghasilan kena pajak (PKP) lebih kecil dari yang sebenarnya dan menghindar dari kemungkinan terungkapnya penyimpangan pajak yang mereka lakukan sekaligus mengantipasi rasa malu bila di kemudian hari perbuatan melakukan penyimpangan pajak tersebut diketemukan oleh petugas pajak. Lebih lanjut Andreoni dkk (1998) mengatakan bahwa ada tiga hal yang membuat penelitian terhadap faktor guilt and shame ini tidak mudah oleh karena adanya hal berikut ini: (a) bagaimana guilt dan shame dapat dipertimbangkan menjadi bagian dari teori ekonomi dan psikologi? (b) faktor guilt and shame tidak bisa diobservasi secara langsung sehingga pengidentifikasian dilakukan sepenuhnya berdasarkan format fungsional asumsi-asumsi, dan (c) perasaan moral secara jelas berperan dalam pengambilan keputusan kepatuhan perpajakan namun bukti penelitian secara empiris tidak begitu jelas. Frey (1992) mengklaim bahwa teori psikologi mengenai intrinsic versus entrinsic motivation juga mempunyai relevansi untuk menjelaskan 
perilaku kepatuhan. Menurut penelitian Frey (1992) bila monitoring dan sanksi denda terhadap ketidakpatuhan perpajakan naik, pembayar pajak memberikan tanggapan bahwa intrinsic motivation juga naik. Hal ini membuktikan intrinsic motivation mempunyai hubungan yang erat dengan perpajakan.

Andreoni dkk (1996) berteori bahwa di dalam public finance, permasalahan tax compliance meliputi equity, efficiency dan incidence. Sebagai contoh, kekayaan negara berupa pajak dapat secara sistemik digerogoti oleh tindak penggelapan pajak (tax evasion) yang mengakibatkan efektifitas sistem perpajakan untuk mengumpulkan kekayaan berupa pajak (equity) menjadi berkurang dari apa yang telah ditetapkan atau di undang-undangkan. Setiap upaya yang dilakukan untuk mengurangi penggelapan pajak merupakan biaya (cost) dan membuat perpajakan tidak efficient. Bentukbentuk penggelapan pajak (cheating) antara lain tidak melaporkan atau melaporkan lebih rendah penghasilan dari penghasilan yang sebenarnya diperoleh pembayar pajak yang melakukan kegiatan usaha pribadi (selfemployed individuals) sehingga pajak penghasilan terhutang atau pajak penghasilan yang harus dibayar lebih kecil dari yang seharusnya, adalah salah satu dari akibat adanya incidence.

Penelitian kepatuhan perpajakan oleh para ahli terdahulu, kebanyakan masih ditujukan kepada pembayar pajak orang pribadi atau individual tax payers bukan pembayar pajak perusahaan. Kalaupun ada penelitian kepatuhan perpajakan pembayarpajak perusahaanjumlahnya masih sedikit seperti yang dikemukakan oleh Crocker dan Slemord (2004). Yang paling banyak dilakukan oleh para peneliti adalah penelitian mengenai faktor-faktor determinants yang mempengaruhi tax compliance, seperti Rice (1992) yang melakukan pengujian sejumlah besar sampel perusahaan berskala menengah di Amerika Serikat. Hasil penelitiannya menyatakan bahwa antara variable evasion dengan variable marginal tax rate terdapat hubungan yang positif tetapi tidak significant. Dia juga menemukan bukti yang sangat kontras dalam hal penyimpangan perpajakan atas laba perusahaan. Yang pertama bahwa perusahaan-perusahaan yang keuntungan usahanya lebih rendah dari rata-rata keuntungan yang diperoleh perusahaan yang diteliti, melakukan penyimpangan perpajakan dengan tujuan memperbaiki kinerja keuangan. Yang ke dua, perusahaan perusahaan dengan laba di atas rata-rata perusahaan yang diteliti, dengan mudah membuat laporan labanya lebih rendah dari laba yang sebenarnya tanpa bisa dideteksi oleh petugas pajak. Dia juga menemukan bahwa penyimpangan perpajakan lebih rendah terjadi di industri di mana peraturan perpajakannya dibuat lebih berat (heavily regulated) atau peraturannya telah dikenal oleh masyarakat luas (publicly traded). Salah satu faktor penyebab belum optimalnya penerimaan pajak di suatu negara menurut berbagai penelitian adalah adanya faktor noncompliance atau ketidakpatuhan para wajib pajak/pembayar pajak terhadap perpajakan. Ketidakpatuhan tersebut bisa dalam berbagai bentuk tindakan pelanggaran seperti penyelundupan pajak (tax evasion), korupsi uang pajak (tax corruption), memperkecil jumlah pajak dari yang seharusnya dibayar (tax cheating), pemalsuan dokumen pajak dan tindak pelanggaran lainnya.

Banyak riset melakukan investigasi penyebab dari mengapa sebagian masyarakat mau membayar pajak dan sebagian lainnya tidak. Misalnya penelitian experiment yang dilakukan oleh Boylan dan Sprinkle (2001), penelitian random surveys oleh Fisher et al., (1989) dan penelitian available tax databases oleh Erard dan Ho (2001) para peneliti tersebut berhasil mengidentifikasi karakteristik pembayar pajak yang tidak patuh dan faktor-faktor yang memotivasi mereka untuk tidak patuh kepada peraturan perpajakan.

Sejalan dengan para peneliti sebelumnya tentang motivasi kepatuhan pembayar pajak, Ritsema, dkk(2003)melakukan penelitian tentang motivasi para pembayar pajak yang tidak patuh dengan mengidentifikasi sekelompok pembayar pajak tidak patuh yang mengikuti Arkansas Tax Penalty Program Tahun 1997 dengan mengajukan dua pertanyaan penelitian (1) Mengapa anda tidak 
membayar pajak yang seharusnya anda bayar? (2) Apa yang menjadi motivasi anda mengikuti program pengampunan pajak? Penelitiannya menghasilkan kesimpulan bahwa kepatuhan perpajakan (tax compliance) dipengaruhi oleh adanya empat faktor yaitu faktor kekurangan uang (lack of money), persepsi Wajib Pajak tentang keadilan perpajakan (perception of tax fairness), kompleksitas peraturan perpajakan, (complexity of tax law), dan ketidakpedulian terhadap kewajiban perpajakan (ignorance of tax due). Lebih lanjut Ritsema dkk berkesimpulan bahwa moralitas bukan merupakan alasan utama mengapa pembayar pajak mau mengikuti program pengampunan pajak dan bahwa petugas pajak hendaknya memperluas publikasi programprogram pembayaran pajak dan beberapa kelompok pembayar pajak yang tidak ikut program pengampunan pajak menyatakan bahwa ketiadaan dana merupakan salah satu faktor yang significant mengapa pembayar pajak melakukan ketidakpatuhan perpajakan. Penelitiannya juga menyimpulkan bahwa persepsi pembayar pajak tentang fairness of the tax system mempengaruhi kemauannya (influence their willingness) untuk melakukan ketidakpatuhan perpajakan.

Penelitian McEwen dan Maiman (1986) menemukan bukti bahwa persepsi pembayar pajak tentang fairness mempengaruhi langsung (directly associated with) compliance, sementara Porcano (1988) dan Yankeloich et al (1984) menemukan bahwa antara compliance dan perceptions of fairness tidak ada hubungannya (no association). Lebih jauh, beberapa peneliti juga telah melakukan penelitian tentang tax fairness, antara lain Gerbing (1988) yang melakukan survei untuk mengidentifikasi variabel keadilan perpajakan (tax fairness) dan menemukan bahwa ada lima faktor yang terkandung dalam tax fairness yaitu (1) dimensi pembebanan pajak yang adil (general fairness/distribution), (2) dimensi kompensasi yang diberikan pemerintah kepada pembayar pajak (exchange with government), (3) dimensi perilaku terhadap kekayaan pembayar pajak (attitude towards taxes of the wealthy) (4) dimensi sistem tarif pajak berjenjang atau tarif pajak tunggal (progressive versus flat tax rate) dan (5) dimensi kepentingan pribadi (self interest). Selain Gerbing (1988), peneliti lain yaitu Christensen, dkk (1994) dan Christensen \& Weirich (1996) juga menemukan lima faktor tax fairness sama dengan Gerbing (1988). Dengan menggunakan metode survei yang dibangun Gerbing (1988), Christensen, dkk (1994) melakukan survei terhadap 296 mahasiswa yang sedang belajar perpajakan. Hasilnya menunjukkan bahwa pada kelompok tersebut variabel tax fairness tersebut juga ada. Christensen, dkk (1996) melakukan pengujian yang sama kepada para auditor, pengajar pajak dan praktisi pajak; di kelompok ini variabel tax fairness juga ditemukan. Penelitian lainnya yang menggunakan metode survei Gerbing dilakukan oleh Richardson (2006) dan Gilligan \& Richardson (2005). Penelitian dilakukan di Hongkong. Richardson (2006) dan Gilligan \& Richardson (2005) menemukan bahwa terdapat perbedaan budaya di Hongkong dengan budaya di Negara Barat tetapi variabel yang sama yaitu tax fairness juga ditemukan di Hongkong. Mereka berdua menemukan faktor ke enam dari tax fairness yaitu faktor pembayar pajak penghasilan kategori menengah (the middle income earners). Penelitian Azmi dkk (2008) terhadap para pembayar pajak di Malaysia juga menemukan kesamaan antara pembayar pajak di Amerika Serikat, Australia, dan Malaysia, mengenai persepsi bahwa variabel tax fairness merupakan hal yang penting seperti dikemukakan sebelumnya oleh Gerbing (1988). Christensen, dkk (1994) dan Christensen \& Weirich (1996), Gilligan \& Richardson (2005), Richardson (2006). Namun yang membedakan penelitian Azmi dkk (2008) dengan para peneliti sebelumnya adalah di Malaysia faktor-faktor tax fairness dikelompokkan hanya menjadi 3 dimensi yaitu (1) Pembayar pajak Malaysia tidak mempersepsikan dimensi exchange with government sebagai suatu dimensi yang terpisah dari general fairness dan tax system; (2) Mereka juga tidak mempersepsikan bahwa dimensi tax rate dan special priviledges for wealthy sebagai hal yang terpisah; dan (3) Adalah dimensi kepentingan pribadi (selfinterest). Satusatunya perbedaan yang bisa dijelaskan adalah 
adanya perbedaan budaya antara pembayar pajak Malaysia dan pembayar pajak di negara lain. Kemungkinan lain yang bisa dijelaskan adalah bahwa beberapa konsep tentang tax fairness mungkin saja dirasakan sebagai hal yang complex untuk dimengerti bagi sebagian besar para pembayar pajak (Sheffrin, 1993).

Gilligan \& Richardson (2005) juga melakukan penelitian empiris guna menguji apakah temuan Gerbing (1988) bahwa kepatuhan perpajakan mempunyai lima dimensi yaitu (1) dimensi pembebanan pajak yang adil (2) dimensi imbalan yang diberikan pemerintah kepada pembayar pajak, (3) dimensi ketentuan perpajakan atas kekayaan wajib pajak, (4) dimensi sistem tarif pajak berjenjang atau tunggal dan (5) dimensi kepentingan pribadi ditemukan di yurisdiksi Asia.

Menurut James (1986) yang mengutip laporan Badan Penerimaan Pajak Amerika Serikat (Internal Revenue Services), dari 22 penelitian yang dilakukan para peneliti baik yang dilakukan di dalam negeri Amerika Serikat maupun yang dilakukan di luar Amerika Serikat disimpulkan setidaknya ada 14 (empat belas ) variabel kunci (key variables) yang mempunyai hubungan (relationship) terhadap tax compliance pembayar pajak individual atau Wajib Pajak perorangan yaitu : (1) Age (2) Sex (3) Education (4) Income Level (5) Withholding Income Source (6) Occupation Status (7) Compliant Peers (8) Ethic (9) Fairness (10) Complexity (11) IRS Contact (12) Sanction (13) Probability of being Detected; and (14) Tax Rate.IU

Berdasarkan beberapa kajian dari penelitian sebelumnya kepatuhan pajak pada penelitian ini dipengaruhi oleh 5 faktor penting yang duji secara empiris yaitu lack of money, tax fairness perception, tax complexity, ignorance of tax due, dan probability of detected. Kekurangan uang, keadilan di bidang perpajakan, kompleksitas peraturan, ketidakpedulian, dan kemungkinan terungkapnya penyimpangan diduga merupakan faktor penting terkait kepatuhan pajak pada industry jasa konstruksi.

\section{Metode}

Penelitian ini merupakan Causal Study, yaitu penelitian causal asymmetrical relationship (Donald \& William, 1995) (1) tipe stimulusresponse relationship dan (2) tipe dispositionbehavior relationship. Penelitian ini juga termasuk penelitian asymmetrical relationships tipe disposition-behavior relationship. Populasi penelitian adalah pengusaha jasa konstruksi. Sampel adalah pengusaha jasa konstruksi yang tergabung dalam GAPENSI, GAPENRI, AKLI dan AKI, Wilayah DKI Jakarta Raya. Jumlah total kuesioner didistribusikan adalah sejumlah 215 kuesioner. Jumlah kuesioner kembali adalah sejumlah 115 kuesioner dan dapat sejumlah 104. Kuesioner yang dikeluarkan dari analisis (tidak dapat diolah) karena pengisian kuesioner tidak lengkap. Variabel yang diteliti mencakup kepatuhan, keadilan di bidang perpajakan, kompleksitas peraturan, ketidakpedulian, dan kemungkinan terungkapnya penyimpangan. Definisi operasional dan pengukuran variable mengacu pada penelitian sebelumnya yaitu Pengujian yang digunakan terdiri dari uji validitas, uji reliabilitas dan Uji model structural. Uji validitas dilakukan dengan menggunakan analisis faktor. Item indikator dikatakan valid jika memiliki nilai Extraction method: principal component analysis dan setiap variable diharapkan memiliki nilai Kaiser-Mayer-Olkun Measure of Sampling Adequacy (KMO MSA) dan Anti Image Correlation lebih dari 0.5. Uji reliabilitas menggunakan uji Cronbach Alpha. Item indikator dikatakan reliable jika nilai cronbach alpha $>0.6$. Uji asumsi klasik yang dilakukan mencakup uji multikolinearitas. Uji multikolineritas menggunaka criteria variance inflation factor, dimana jika nilai VIF $<10$ maka dikatakan bahwa tidak terjadi korelasi antar variable independen. Uji hipotesis bagian pertama didasarkan pada hasil uji model structural. Variabel dikatan berpengaruh jika nilai t-hitung > t-tabel. Pengujian hipotesis kedua menggunakan uji beda sampel berpasangan, dimana data yang diuji adalah data sebelum dan sesudah diberlakukannya Peraturan Pemerintah Nomor 
40 Tahun 2009 Tentang Perubahan Peraturan Pemerintah Nomor 51 Tahun 2008 Tentang Pajak Penghasilan Atas Penghasilan Dari Usaha Jasa Konstruksi.

\section{Hasil Penelitian dan Pembahasan}

Berdasarkan data profil perusahaan responden dapat disimpulkan bahwa mayoritas responden, mengerjakan proyek pelaksanaan konstruksi, dan bergerak di sektor bangunan gedung, jalan dan jembatan, berkualifikasi sebagai perusahaan yang memiliki sertifikat dari LPJKN menjadi anggota asosiasi jasa konstruksi. Menurut laporan GAPENRI, anggotanya memiliki kekayaan bersih antara $\mathrm{Rp}$ 0,3 trilyun sampai dengan Rp 1,4 trilyun dan menurut laporan AKI, anggotanya memiliki kamampuan keuangan atau modal kerja antara Rp 0,5 sampai dengan Rp 8,6 trilyun. GAPENSI tidak memberikan informasi mengenai keadaan atau kemampuan keuangan para anggotanya.

Data profil individu yang mewakili manajemen perusahaan, mengisi dan menjawab kuesioner penelitian, adalah: laki-laki, berpendidikan sarjana (S1 atau S2), berusia 26-40 tahun, memiliki jabatan sebagai anggota direksi (direktur utama atau direktur keuangan), memiliki masa kerja di perusahaan antara 5 sampai dengan 10 tahun, dan bekerja di kantor pusat. Data profil individu yang mewakili perusahaan yang mengisi dan menjawab kuesioner penelitian dianggap penting oleh peneliti karena mereka adalah representasi dari perusahaan. Peneliti berkepentingan mengetahui latar belakang dan kompetensi mereka di dalam menjawab setiap pertanyaan yang diajukan dalam kuesioner penelitian agar hasil penelitin ini sesuai dengan yang peneliti harapkan.

Uji validitas dilakukan untuk mengetahui seberapa jauh alat ukur dapat mengungkap dengan benar gejala atau sebagian gejala yang hendak diukur, artinya tes tersebut mengukur apa yang seharusnya diukur. Suatu alat ukur dapat dikatakan mempunyai validitas tinggi apabila alat ukur tersebut menjalankan fungsi ukurnya atau memberikan hasil ukur yang sesuai dengan maksud dilakukannya pengukuran tersebut (Hermawan, 2003).

Uji analisis faktor ini dilakukan terhadap nilai pada setiap variabel dengan menggunakan Extraction method: principal component analysis dan setiap variable diharapkan memiliki nilai Kaiser-Mayer-Olkun Measure of Sampling Adequacy (KMO MSA) dan Anti Image Correlation 0.5 (Hair et al, 2006) dan penelitian ini juga menggunakan Bartlett's test. Rangkuman hasil uji validitas sebagaimana Tabel 1 .

Tabel 1. Hasil Tes Validitas

\begin{tabular}{clcc}
\hline No. & \multicolumn{1}{c}{ Variabel } & Nilai KMO & Keterangan \\
\hline 1 & Tax Compliance & 0.725 & Valid \\
2 & Lack of Money & 0.500 & Valid \\
3 & Tax Fairness Perception & & \\
& - General Fairness & 0.645 & Valid \\
& - Self Interest Dimension & 0.752 & Valid \\
& - Special Dimension & 0.569 & Valid \\
& - Tax Rate Dimension & 0.546 & Valid \\
& - Exchange w Government Dimension & 0.614 & Valid \\
4 & Tax Complexity & 0.662 & Valid \\
5 & Ignorance of Tax Due & 0.500 & Valid \\
6 & Probability of Detected & 0.500 & Valid \\
\hline
\end{tabular}


Uji Reliabilitas Data yang menunjukkan sejauh mana suatu alat pengukur dapat dipercaya atau dapat diandalkan. Pengukuran dianggap andal, jika menunjukkan tidak adanya bias atau bebas dari kesalahan dan menjamin konsistensi ukuran sepanjang waktu (Sekaran 2003, 203). Menurut Malhotra (2004, 167) reliabilitas merupakan keadaan di mana skala menghasilkan hasil yang konsisten jika dilakukan pengulangan pengukuran. Dalam penelitian ini uji keandalan diukur dengan menggunakan koefisien alfa atau Cronbach's alpha. Keandalan atas variabelvariabel yang ada, didasarkan pada nilai koefisien alphayang dihasilkannya. MenurutSekaran(2003, 311) semakin mendekati 1,0 koefisien reliabilitas, semakin baik suatu instrumen. Jika koefisien reliabilitas kurang dari 0,60 dipertimbangkan buruk, dikisaran 0,70 dipertimbangkan cukup, dan jika lebih besar dari 0,80 maka dipertimbangkan baik. Tabel 2 menunjukkan hasil uji reliabilitas dengan menggunakan SPSS versi 15.

Tabel 2. Reliabilitas Masing-Masing Variabel

\begin{tabular}{llcl}
\hline No. & \multicolumn{1}{c}{ Variabel } & $\begin{array}{c}\text { Nilai } \\
\text { Cronbach } \\
\text { Alpha }\end{array}$ & Keterangan \\
\hline 1 & Kepatuhan & 0.716 & Reliabel \\
2 & Lack of Money & 0.950 & Reliabel \\
3 & General Fairness & 0.662 & Reliabel \\
4 & Self Interest & 0.776 & Reliabel \\
5 & Special Tax & 0.770 & Reliabel \\
& Preveledge & & \\
6 & Tax Rate & 0.644 & Reliabel \\
7 & Imbalan & 0.744 & Reliabel \\
& Kompleksitas & & \\
8 & Kepedulian & 0.788 & Reliabel \\
9 & Prob of Detected & 0.799 & Reliabel \\
\hline
\end{tabular}

Menurut Hair et al., (2006) untuk mengukur multikoliniaritas dapat menggunakan nilai VIF (Variance Inflation Factors). Bila nilai VIF $<=5$ maka tidak terdapat multikoliniaritas antar variabel independen. Pada Tabel 3 diperoleh nilai VIF masing-masing 2.183 (Lack of Money), 1.250 (Tax Fairness Perception), 1.905 (Tax Complexity) dan 1.481 (Ignorance of Tax Due) dan nilai Tolerance masing-masing 0,458 (Lack of Money), 0,800 (Tax Fairness Perception), 0,525 (Tax Complexity) dan 0,034 (Ignorance of Tax Due).Nilai batas toleransi (tolerance) yang biasa dipakai dalam penelitian adalah 0,10 atau setara dengan nilai VIF 10 (Suliyanto, 2005:75) Bila menggunakan nilai VIF diisimpulkan bahwa tidak ada kolinearitas antar variabel oleh karena nilai VIF masing-masing variabel dibawah 5. Tetapi bila nilai yang digunakan adalah nilai toleransi, nilai toleransinya diatas 0,10 . Hasil Uji multikolinearitas adalah sebagai berikut pada Tabel 3.

Tabel 3. Hasil Uji Multikolinearitas

\begin{tabular}{lc}
\hline \multicolumn{1}{c}{ Variabel } & Nilai VIF \\
\hline LOM = Lack of Money & 2.183 \\
TFP $=$ Tax Fairness Perception & 1.250 \\
TC $=$ Tax Complexity & 1.905 \\
ITD $=$ Ignorance of Tax Due & 1.481 \\
\hline
\end{tabular}

Pengujian hipoptesis bagian pertam dilakukan dengan uji regresi berganda dengan bantu uji model structural. Sebelum menganalisis hipotesis penelitian yang diajukan, terlebih dahulu dilakukan pengujian kesesuaian model (goodness of fit model). Pengujian kesesuaian model dilakukan dengan melihat beberapa kriteria pengukuran. Salah satu alat uji yang dapat digunakan untuk mengukur overall fit adalah dengan menggunakan Root Mean Square Error of Approximation (RMSEA) RMSEA adalah sebuah indeks yang dapat digunakan untuk mengkompensasikan chi square statistik. Nilai RMSEA yang dapat diterima adalah kurang dari 0,08 (Hair et al., 2006). Dalam penelitian ini diperoleh nilai RMSEA 0.0000 yang berarti model ini dinyatakan fit untuk digunakan dalam penelitian ini. Dari analisis SEM dihasilkan gambar T-Value Diagram, dimana diperole nilai Chi-Square $=0,00 ; \quad \mathrm{df}=0 ; \quad$ P-Value 1,$000 ;$ dan RMSEA $=0,000$. Berdasarkan analisis chi-square, dalam penelitian ini model dikatakan layak ( goodness of FIT) karena memperoleh nilai chi-squares 0,00 yang berarti lebih kecil dari nilai chi-suare kritisnya (alpha $=0,5)$. Kelayakan model juga bisa dilihat dari nilai P-value. Dalam 
penelitian ini diperoleh nilai $\mathrm{p}$-value $=1,00000$ yang berarti p-value lebih besar dari 0,5 (nilai alpha), maka hipotesis nol bahwa model adalah layak diterima. Berdasarkan analisis RMSEA diperoleh nilai RMSEA 0,000 ysng berarti model adalah layak karena nilai RMSEA lebih kecil dari $\leq 0,08$.
Pengujian pengaruh masing-masing variable independen (kekurangan uang, keadilan di bidang perpajakan, kompleksitas peraturan, ketidakpedulian, dan kemungkinan terungkapnya penyimpangan) terhadap kepatuhan pajak terangkum pada Tabel 4 dan Gambar 1.

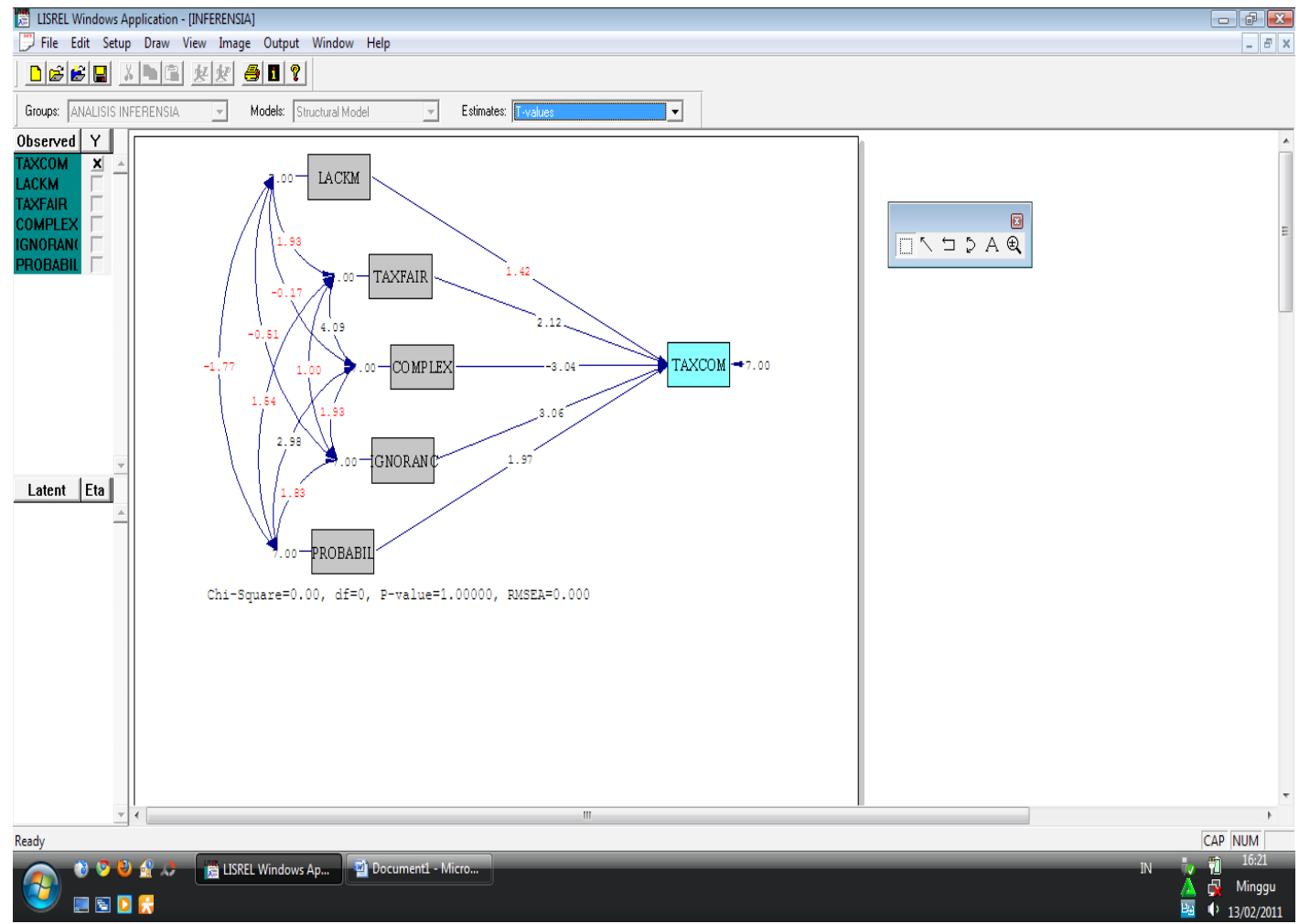

Gambar 1. Hasil Uji Structural Equation Modelling

Tabel 4. Hasil Uji Hipotesis Pertama

\begin{tabular}{ccccl}
\hline Hipotesis & Variabel & t observasi & t tabel & Keputusan \\
\hline H1 & LoM $\rightarrow$ Tax Com & 1.42 & 1.6573 & Ho diterima \\
H2 & TaxF $\rightarrow$ Tax Com & 2.12 & 1.6573 & Ho ditolak \\
H3 & TaxC $\rightarrow$ Tax Com & 3.04 & 1.6573 & Ho ditolak \\
H4 & Igno $\rightarrow$ Tax Com & 3.06 & 1.6573 & Ho ditolak \\
H5 & Prob $\rightarrow$ Tax Com & 1.97 & 1.6573 & Ho ditolak \\
\hline
\end{tabular}


Berdasarkan hasil pengujian, ditemukan bahwa kepatuhan pajak pada industry jasa konstruksi dipengaruhi/ditentukan oleh 4 dari 5 faktor yang diuji yaitu keadilan di bidang perpajakan, kompleksitas peraturan, ketidakpedulian, dan kemungkinan terungkapnya penyimpangan. Berdasarkan hasil pengujian, kekurangan uang tidak terbukti sebagai faktor penentu kepatuhan pajak.

Pengujian hipotesis kedua dilakukan dengan menggunakan uji beda. Uji perbedaan sebelum dan sesudah tahun 2008 dengan data kuartalan 5 (lima) perusahaan responden Tbk yang tercatat di Bursa Efek Indonesia yang ada data pajaknya pada Laporan Keuangan yang telah dipublikasikan. Dengan menggunakan data pajak yang dibayar 2006-2008 dibandingkan data pajak yang dibayar 2009 dan kwartal 2 tahun 2010 mendapatkan nilai signifikansi sebesar 0.064. Penelitian ini menggunakan tingkat signifikansi 0,100 sehingga Ho ditolak, yang berarti ada perbedaan antara sebelum dan sesudah diberlakukannya peraturan pajak tahun 2008 (sebelum periode 2006 sampai dengan 2008; sesudah tahun 2009 sampai dengan kwartal 2 tahun 2010). Berdasarkan hasil tersebut, maka dapat disimpulkan bahwa terdapat perbedaan jumlah pajak sebelum disbanding sesudah pemberlakukan regulasi bartu terkait jasa pajak konstruksi.

Penelitian Risma dkk (2003) mengemukakan bahwa faktor lack of money merupakan faktor yang significant mempengaruhi kepatuhan perpajakan Wajib Pajak Arkansas USA, sedangkan dalam penelitian ini faktor lack of money merupakan faktor yang pengaruhnya terhadap kepatuhan perpajakan Wajib Pajak di Indonesia sangat kecil. Menurut Andreoni (1998) pada program tax amnesty pembayar pajak yang tidak patuh diijinkan membayar hutang pajaknya dan biasanya beserta bunganya guna menghindari hukuman tindak pidana pelanggaran perpajakan dan membayar sebagian atau semua denda yang dibebankan. Leon Yudkin ( Zain,2007) berasumsi bahwa Wajib Pajak selalu berusaha untuk membayar pajak yang terhutang sekecil mungkin, sepanjang hal itu dimungkinkan oleh ketentuan peraturan perundang-undangan perpajakan dan bahwa para Wajib Pajak cenderung untuk menyelundupkan pajak (tax evasion) yaitu usaha penghindaran pajak yang terhutang secara illegal, sepanjang Wajib Pajak tersebut mempunyai alasan yang meyakinkan bahwa akibat dari perbuatannya tersebut kemungkinan besar mereka tidak akan dihukum serta yakin pula bahwa rekan-rekannya melakukan hal yang sama.

Dugaan peneliti, perbedaan sikap orang Amerika terhadap membayar kewajiban pajaknya dalam kasus Tax Amnesty di Arkansas dengan Wajib Pajak Indonesia terletak pada perbedaan kasus ketidak patuhannya yang bisa dijelaskan sebagai beikut:

1) Pembayar pajak di Arkansas mengetahui bahwa dengan mengikuti Program Tax Amnesty mereka akan diberikan keringanan hukuman dibidang perpajakan, sehingga pembayar pajak di Arkansas mau berterus terang didalaam mengisi pertanyaan kuesioner penelitian yang disodorkan petugas pajak saat mengajukan Tax Amnesty bahwa mereka tidak membayar pajak karena kekurangan uang;

2) Dalam Penelitian ini, Wajib Pajak di Indonesia tidak dalam situasi yang sama dengan para pembayar pajak di Arkansas. Pertanyaan kuesiomer apakah kekurangan uang menjadi dorongan untuk melakukan penyimpangan perpajakan, oleh Wajib Pajak Indonesia dijawab tidak significant mempengaruhi kepatuhan perpajakannya. Dugaan peneliti, sangat boleh jadi karena Wajib Pajak Indonesia yang mengembalikan kuesioner penelitian sebagian besar adalah perusahaan yang memiliki kemampuan merencanakan keuangan yang baik ( Horne, 1998) sehingga faktor kekurangan uang dalam konteks kepatuhan perpajakan bagi mereka tidak relevan. Untuk memperoleh jawaban yang lebih meyakinkan peneliti menyarankan agar pengaruh kekurangan uang terhadap kepatuhan perpajakan ini diteliti lagi dengan lebih mendalam.

Penelitian Ritsema dkk (2003) menyatakan bahwa faktor ketidak- sengajaan 
dan kurangnya pengetahuan Wajik Pajak menyebabkan ketidakpedulian Wajib Pajak di Arkansas USA. Dalam penelitian ini selain kurangnya pengetahuan Wajib Pajak tentang perpajakan, ditemukan fakta baru bahwa ketidakpedulian perpajakan Wajib Pajak perusahaan Jasa Konstruksi di Indonesia juga disebabkan oleh faktor dimilikinya kewenangan untuk menetapkan besarnya pajak terhutang oleh pemeriksa pajak secara jabatan yang oleh Wajib Pajak dipersepsikan tidak adil.

Berdasarkan pengalaman praktis di lapangan hal-hal yang disetujui maupun yang tidak disetujui dinyatakan dalam Berita Hasil Pemeriksaan. Wajib Pajak akan menerima Surat Ketetapan Pajak yang menyatakan besarnya pajak terhutang, besarnya tunggakan pajak atau besarnya pajak lebih bayar berdasarkan laporan Berita Hasil Pemeriksaan dan denda yang harus dibayar. Masalah timbul jika ketetapan perpajakan yang tercantum di Surat Ketetapan Pajak berbeda dengan apa yang diharapkan oleh Wajib Pajak apalagi jika selisih nilainya besar. Disinilah perselisihan pajak biasa terjadi. Bila tidak ada titik temu, maka Wajib Pajak akan mengajukan keberatan, banding dan/atau gugatan pajak atau menawarkan kompromi dengan pemeriksa pajak yang merugikan penerimaan negara dan menguntungkan pihak pemeriksa dan Wajib Pajak. Penawaran kompromi tidak selalu datang dari Wajib Pajak Peristiwa kompromi ini menurut pendapat Frey (1992) adalah suatu fenomena sosial yang umum terjadi di masyarakat diseluruh dunia walaupun tindakan tersebut sebenarnya merupakan pelanggaran atas norma-norma dan etika perpajakan yang berlaku bahwa wajib pajak harus melaksanakan kepatuhan perpajakan dan pemeriksa pajak harus berlaku adil dan bertindak professional.

Hasil analisis tax fairness faktor loading terhadap dimensi variabel tax fairness masingmasing nilai KMO Bartlett's Test adalah berikut ini: general fairness 0.645 , self interest 0.752 , special dimension 0.569 , tax rate 0.546 dan exchange with government 0.614 Dengan demikian dapat disimpulkan bahwa lima dimensi persepsi pajak yang adil juga ditemukan pada
Wajib Pajak Jasa Konstruksi di Indonesia. Hal ini dibuktikan dengan fakta bahwa berdasarkan hasil pengumpulan kuesioner setelah dilakukan analisis masing-masing dimensi memperoleh nilai validitas data di atas nilai KMO 0,5 yang disarankan oleh Hair et al., 2006.

Penelitian ini membuktikan bahwa lima dimensi dari persepsi perpajakan yang adil juga terdapat pada Wajib Pajak Jasa Konstruksi di Indonesia. Seperti kesimpulan penelitian Azmi dkk (2003) dan Perumal (2008), penelitian ini menemukan kesamaan antara Amerika Serikat, Australia, dan Malaysia, mengenai persepsi bahwa variabel tax fairness merupakan hal yang penting seperti dikemukakan sebelumnya oleh Gerbing (1988). di USA dan peneliti lain. Perbedaannya dengan penelitian di negara lain, dimensi perpajakan yang adil yang terdapat pada Wajib Pajak Jasa Konstruksi di Indonesia berbeda dengan para pembayar pajak di Malaysia (Azmi dkk 2008) karena di Malaysia dimensi perpajakan yang adil dikelompokkan hanya menjadi tiga dimensi. Pembayar pajak Malaysia tidak mempersepsikan faktor exchange with government sebagai suatu faktor yang terpisah dari general fairness dan tax system. Mereka juga tidak mempersepsikan bahwa tax rate dan special privileges for wealthy sebagai hal yang terpisah.

Perbedaan jumlah rata-rata Pajak Penghasilan yang dibayar oleh Wajib Pajak perusahaan Jasa Konstruksi sebelum dan sesudah Peraturan Pemerintah Nomor 51 Tahun 2008 / Nomor 40 Tahun 2009 Tentang Pajak Penghasilan Final atas Penghasilan dari Perusahaan Jasa Konstruksi. Penelitian Uji Beda menemukan bukti bahwa berdasarkan data pajak yang dibayar oleh perusahaan sampel, antara jumlah pajak yang dibayar pada tahun 2006-2008 (sebelum PP 51/2008/PP 40/2009 diberlakukan) dengan jumlah pajak penghasilan yang dibayar pada periode 2009 sampai kuartal II tahun 2010 ( sesudah PP 51/2008/PP 40/2009 diberlakukan) ternyata terdapat perbedaan yang signifikan. Dengan kata lain bahwa penyempurnaan regulasi perpajakan terkait pajak jasa konstruksi terbukti efektif dan berhasil. 


\section{Kesimpulan, Keterbatasan, dan Implikasi Hasil Penelitian}

Ritsema, dkk (2003) dan IRS of USA (1986) menyatakan bahwa bahwa kekurangan uang, keadilan, kompleksitas, ketidakpedulian dan kemungkinan terungkapnya penyimpangan terhadap kepatuhan perpajakan, juga ditemukan dalam penelitian kepatuhan perpajakan Perusahaan Jasa Konstruksi di Indonesia; Penelitian menyimpulkan pengaruh kekurangan uang terhadap kepatuhan perpajakan perusahaan Jasa Konstruksi, ada ; tetapi sangat kecil. Terdapat peningkatan kepatuhan Wajib Pajak Jasa Konstruksi terhadap pembayaran Pajak Penghasilan sesudah di implementasikannya PP 51/2008.

Keterbatasan penelitian adalah jumlah perusahaan sampel pembayar Pajak Penghasilan untuk analisis Uji Beda belum optimal oleh karena data yang tersedia di Bursa Efek Indonesia hanya beberapa perusahaan. Dalam penelitian ini peneliti hanya mengambil dan meneliti 3 dari 14 variabel exogeneous yang menurut penelitian IRS - USA (James \& Simon R, 1986) mempengaruhi variabel endogeneous kepatuhan perpajakan yaitu variabel (1) variabel tax fairness (2) variabel tax complexity (3) variabel probability of being detected, sedangkan 2 variabel exogeneous lainnya yaitu variabel lack of money dan ignorance of tax due merupakan variabel exogeneous hasil temuan Ritsema $d k k$ (2003) sehingga jumlah variabel exogeneous yang mempengaruhi variabel endogeneous kepatuhan perpajakan dalam penelitian ini menjadi 5 variabel yaitu: lack of money, tax fairness, tax complexity, ignorance of tax due dan probability of being detected.

Temuan penelitian meyatakan bahwa faktor ketidakpedulian perpajakan di Indonesia juga ditemukan patut diduga disebabkan oleh persepsi Wajib Pajak terhadap kewenangan petugas pemeriksa pajak untuk memutuskan dan menetapkan besarnya jumlah pajak terhutang secara jabatan yang seringkali penetapannya sangat jauh berbeda dengan perhitungan yang dibuat Wajib Pajak sehingga dipersepsikan oleh
Wajib Pajak hal tersebut tidak adil, diharapkan dapatmenjadiperhatian dan pemikiran Pemerintah selaku pembuat kebijakan perpajakan (perlu diperketat pengawasannya agar kewenangannya tidak disalahgunakan oleh oknum aparat pajak yang kurang bertanggung-jawab yang dapat mengakibatkan sikap pesimistis, apatis dan skeptis para Wajib Pajak untuk mematuhi perpajakan di Indonesia).

Temuan kajian ini diharapkan dapat memberikan kontribusi kepada Wajib Pajak perusahaan Jasa Konstruksi Indonesia agar kepatuhan perpajakan Wajib Pajak di sektor usaha Jasa Konstruksi di Indonesia bisa lebih baik lagi dan meninggalkan sikap pesimistis, apatis dan skeptis yang selama ini menghinggapi para Wajib Pajak untuk mematuhi perpajakan di Indonesia.

\section{Daftar Pustaka}

Andreoni., James., Erard, B., \& Feinstein, J. (1998). Tax compliance. Journal of Economic Literature, Vol.36, No.2 ,pp. 818-860.

Babbie., E. (1990). Survey Research Methods. Wadsworth Publishing Conpany Belmont, California of USA.

Boguslavskiy., V. (2009). Achieving integrity in tax administration. Polish Academy of Science, 2009.

Brooks Neil (2001). Key Issues In Income Tax: Challenges of Tax Administration and Compliance. Asian Development Bank 2001 Tax Conferences.

Che Azmi Anna. A and Perumal. Kamala A. ( Oct-Nov,2008). Tax Fairness Dimensions In An Asian Context: the Malaysian Perspective. The International Review of Business Research papers Vol.4 No.5. OctoberNovember 2008 pp.11-19

Devano, Sony (2006). Perpajakan, Konsep, Teori dan Isu. Prenada Media Group, Jl Lele I No 7 Rawamangun Jakarta 13220 Indonesia.

Emory, C, William., Cooper, R, Donald., (1995). Business Research Methods. USA: The McGraw-Hill Companies,Inc,.

Fjeldstad Odd Hedge (2005). Corruption in tax administration: Lessons from institutional 
reforms in Uganda. CHR Michelsen Institute,Berge,Norway. WP 2005:10.

Gilarso, T. (2004). Benefit Principle "Adam Smith (1776) \& General Theory of Employment,Interest and Money, Keyness(1925-1936); New Keynesian (1970).

Harold, M.S (1951). Competition From TaxExempt Business: Discussion . The Journal of Finance, Vol. 6, No. 2., pp. 178-186

Horne, J. V. (1998). Financial Management Policy. New Jersey of USA: Prentice-Hall, Inc.

Jackie., Jeffrey, K., Mason., \& Gordon., Robert H. (Jun., 1997). How Much Do Taxes Discourage Incorporation? The Journal of Finance, Vol. 52, No. 2., pp. 477-505

Jit B.S. Gill (2003). The Nuts and Bolts of Revenue Administration Reform. Lead Public Sector Management Specialist Europe and Central Asia region",2003.

Katz, Jeffrey P, et al (2006):" If we could chose the way we pay : The Impact of Decision Complexity On Tax Scheme Preference Journal of Applied Business Research-Third Quarter 2006.

Leroy Marc (2009). Tax Sociology Sociopolitical Issues for a Dialogue with Economists. Tax Sociology, http://socio-logos.revues.org/ document2073.html, 7/2/2009

MacKie-Mason, Jeffrey, (Dec., 1990). Do Taxes Affect Corporate Financing Decisions? The Journal of Finance, Vol. 45, No. 5, pp. 14711493

Nur-tegin D Kqanybek((2008). Determinants of Business Tax Compliance. The B.E.Journal of Economic Analysis \& Policy", Vol 8, Issue 1,Article 18.pp 1-26.

OECD (2006). Sharing Knowledge of Developments and Reforms in revenue Bodies and Meeting the Challenges of International Non-Compliance with Domestix Tax Laws. The $3^{\text {rd }}$ Meeting of the OECD Forum On Tax Administration,Seoul,14-15 September 2006.

Pauline Niemirowskiand Alexander J Wearing (2004). Do Australian Taxation Office Staff and Compliant Taxpayers Identify with Tax From The Same Perspective, or Are There significant degrees of Separation? The http:// austlii.edu.au/journal/JATax/2006/4,html.

Peratuan Pemerintah Nomor 40 Tahun 2009 Tentang Perubahan atas Peraturan Pemerintah nomor 51 Tahun 2008 tentang Pajak Penghasilan atas Penghasilan Dari Usaha Jasa Konstruksi.

Peraturan Direktur Jenderal Pajak Nomor PER70/PJ./2007 Tentang Jenis Jasa Lain Dan Perkiraan Penghasilan Neto Sebagaimana Dimaksud Dalam Pasal 23 ayat (1) huruf C Undang-undang Nomor 7 Tahun 1983 Tentang Pajak Penghasilan Sebagaimana Telah beberapa kali Diubah Terakhir Dengan Undang-undang Nomor 17 Tahun 2000.

Peraturan Menteri Keuangan Republik Indonesia Nomor 187/PMK.03/2008 Tentang Tata Cara Pemotongan,Penyetoran, Pelaporan, $D$ an Penatausahaan Pajak Penghasilan Atas Penghasilan Dari Usaha Jasa Konstruksi Biro Umum Departemen Keuangan Republik Indonesia,2008.

Peraturan Pemerintah Indonesia Nomor 51 Tahun 2008 Tentang Pajak Penghasilan Atas Penghasilan Dari Usaha Jasa Konstruksi Lembaran Negara Republik Indonesia Tahun 2008 Nomor 109.

Peraturan Pemerintah Republik Indonesia Nomor 140 Tahun 2000 Tentang Pajak Penghasilan Atas Penghasilan Jasa Konstruksi Lembaran Negara Republik Indonesia Tahun 2000 Nomor 255.

Perundang-undangan dan Peraturan Perpajakan \& Pajak Penghasilan atas Penghasilan Dari Usaha Jasa Konstruksi di Indonesia.

Phillips Max Everest (2008). Business tax as state-building in developing countries : applying governance principles in private sector development. International Conference on Tax and State Building,hosted by the Government of South Africa,28-29 Augudt 2008.

Ritsema, Christina, et al (June 2003). Economic And Behavioral Determinants of Tax Compliance: Evidence from 1997 Arkansas 
Tax penakty Amnesty Program. IRS Research Conference,June 2003, The html version of the file http://apps3.irs.gov/pub/irs-soi/ ritsema.pdf

Simon, Herbert A (1998). Why Public Administration? Simon Journal of Public Administration Research and Theory -1998.

Undang-undang Nomor 28 Tahun 2007 Tentang Perubahan Ketiga Atas Undang-undang Nomor 6 Tahun 1983 Tentang Ketentuan Umum Dan Tata Cara Perpajakan Lembaran Negara Republik Indonesia Tahun 2007 Nomor 85.

Undang-undang Nomor 36 Tahun 2008 Tentang Perubahan Keempat Atas Undang-Undang Nomor 7 Tahun 1983 Tentang Pajak Penghasilan Lembaran negara Repuyblik Indonesia Tahun 2008 Nomor 133.

Widarjono, Agus ( 2010). Analisis Statistika MULTIVARIAT TERAPAN. Yogyakarta: Unit Penerbit Dan Percetakan Sekolah Tinggi Ilmu Managemen YKPN.

Zain, Mohhammad (2008). Manajemen Perpajakan. Edisi 3, Jakarta: Penerbit Salemba Empat.

Zodrow, George.R. (1999). Incidence of Taxes, The Encyclopedia of Taxation and Tax Policy, Urban Institute Press. 